\title{
Value Knowledge, Institutional Essence and Economic Growth
}

\author{
Shangyi Zhang ${ }^{1}$ \\ ${ }^{1}$ Department of Economics and Trade, School of Management, Chongqing Jiaotong University, Chongqing, \\ China \\ Correspondence: Shangyi Zhang, Department of Economics and Trade, School of Management, Chongqing \\ Jiaotong University, Chongqing, China.
}

Received: November 29, 2018

Accepted: January 2, 2019

Online Published: January 21, 2019

doi:10.5539/ibr.v12n2p135

URL: https://doi.org/10.5539/ibr.v12n2p135

\begin{abstract}
Knowledge can be divided into knowledge about technology and knowledge about value. The per capita distribution level of value knowledge determines the evolution of the system. Therefore, the essence of institution is value knowledge, and the evolution of institution depends on the variance of knowledge distribution per capita and the number of people. The economic system mapped by the level of value knowledge provides certainty for the introduction of economic technology, and finally achieves economic growth in the modern sense.
\end{abstract}

Keywords: value knowledge, knowledge distribution, institutional essence, economic growth

\section{The Epistemological Basis of Economic Growth}

In economic research, we should pay more attention to the role of knowledge in economic growth than the mainstream of Economics, while the mainstream schools of economics express less. If we want to make some traces, we can find that neoclassicism recognizes the role of knowledge in growth to a certain extent. Marshall clearly put forward that "the majority of capital is made up of knowledge and organizational structure...... Knowledge is our most powerful driving force of production" (Marshall, 1983). however, in most economic studies, these conclusions are often ignored, and more attention is paid to capital, labor, technology, management and other factors, thus forming a diminishing effect of growth, and even thinking that economic growth is limited. The role of knowledge in economic growth is particularly advocated by the Austrian school. Hayek specializes in discussing the relationship between economics and knowledge. He holds that "in economic theory, the empirical factor, which involves not only meaning but also causes and results, is the only factor that draws a conclusion as a result of it, is derived from some relevant factors. The proposition of knowledge acquisition is composed of "(Hayek,1989). Since there is no limit to the growth of human knowledge, there is no limit to the growth driven by knowledge. As Romer pointed out, "the long-term growth is mainly driven by the knowledge accumulation of the forward-looking and profit-maximizing firms"(Rome, 1986). From this, we can deduce an increasing effect of knowledge on economic growth. However, it is worth noting that even considering the spillover effect of knowledge, in the analysis of relevant knowledge and economic growth, knowledge can play a role in promoting economic growth in a socio-economic region, but it can not achieve the same effect or even the opposite effect when applied to other socio-economic regions. Prescott made a clear statement: "In fact, the available knowledge of all countries is the same. Therefore, there must be some other factor, or a series of factors that lead to the difference of total factor productivity" (Palente, Prescott, 2013). The key point is that different socio-economic regions have different institutional rules constructed by value knowledge. Here, we can continue North's research and regard knowledge as a grasp of uncertainty, which is embodied in the accumulation of technical knowledge and human value knowledge, so that uncertainty can be determined to a certain extent, and then promote economic growth. After making such a distinction, one can also observe that knowledge about technology is scalar knowledge and knowledge about human value is vector knowledge (zhang shangyi, 2014). This is because the knowledge about human value will eventually give a value orientation about human behavior, and then construct rules that are compatible with value knowledge. In this regard, Leibniz also divided knowledge into knowledge about facts and knowledge about reason (Schneewind, 1990). Rationality affects people's behavior, which can be understood as a value choice of behavior. When an individual chooses the direction of value, according to North's understanding, it is the change of belief, which is actually the change of direction of recognition of interests corresponding to human value knowledge. As the author pointed out in the 
previous article(Zhang Shangyi, 2014), because human knowledge about value is vector knowledge, the change of acquiring new knowledge will not only lead to the change of behavior intensity, but also to the change of direction, which is reflected in the selective change of behavior. This change depends on this kind of knowledge. Slope level of total amount. The coordinate system can be used to illustrate that when the position of the new knowledge is set on the $\mathrm{x}$-axis, when the angle between the knowledge stock and the $\mathrm{x}$-axis is greater than 90 degrees, an opposite vector will appear, which reduces the intensity of the directionality of behavior; on the contrary, when the angle between the knowledge stock and the x-axis is less than 90 degrees, a positive vector phase will be formed. Additionally, it strengthens the restriction of directionality of behavior. Moreover, the smaller the angle between the new knowledge and the x-axis, the greater the superposition effect of the new knowledge on the knowledge stock. On this basis, we can better understand North's proposition that "human capital refers to the knowledge that human beings possess, which is rooted in people's beliefs, and the system that human beings create to reflect their beliefs" (North,2013). Here, the system is attributed to the result of knowledge about human value. Then, the system problem is no longer the concept of knowledge, but the result of different types of human knowledge. Thus, in human capital, the distinction between knowledge and system is not necessary, but is unified with human knowledge about technology and value. In the relevant knowledge system, we can better understand that in North's argument, whether beliefs or institutions, should be the result of the superposition of human knowledge vectors about value.

As a matter of fact, it has been argued that "people's economic activities and how to achieve a balanced coexistence of these activities will begin with their knowledge of the world"(Zhang Shangyi, 1998), and that knowledge about the world can be divided into two aspects. Knowledge about human value is embodied in knowledge tradition in the crowd. This knowledge tradition can be solidified into system rules and embodied in human grasp of value. Knowledge about technology can be transformed into technical knowledge and embodied in human use of technology. By dividing knowledge into two aspects, we can try to understand Schultz's emphasis that "history has proved that we can increase resources through the progress of knowledge"(Schultz, 1990). Here, the question to be solved is why the progress of knowledge can increase resources and thus promote economic growth. North has discussed this problem, that is, the growth of knowledge makes uncertainty certain. Human beings are constantly improving their grasp of technology and value, so economic growth can be achieved through controllable measures. Specifically, knowledge about technology can make the uncertainty of technology more definite through technological progress. This is because technological progress not only enables people to understand technology, but also enables people to invest in it. Source supply has been increased, and technical knowledge beneficial to economic and social growth can be developed, so as to achieve certainty of economic growth at the technical level, reflecting the positive effect of technological progress on economic growth, which has been demonstrated in Solow's research, such as Solow's empirical research. It is indeed pointed out that during a period of economic growth in the United States, "the cumulative technological change in the production function is about $80 \%$. So there is reason to think that in total output growth... $7 / 8$ is the result of technological change "(Solow, 1991). However, Solow pointed out that growth is only a short-term growth, "a major source of long-term economic change is structural change" (North, 1994), and the organizational structure is ultimately reflected in the rules of the system. In this regard, it can be considered that the institutional structure of a socio-economic region restricts technological progress and economic growth, which can be proved by the practice of economic growth in some countries and regions of the world. Institutional structure is in fact the determination of uncertainty about human behavior, which is embodied by knowledge of human value, while at the level of knowledge, it is embodied by knowledge tradition, which directly affects people's behavior patterns. Therefore, there will be "people from different cultural backgrounds have different opinions on the same thing. Understanding makes different choices"[8] p62, which depends on the cultural traditions constructed by different knowledge of human values. Therefore, how to develop an understanding of the distribution and certainty of this knowledge has become a fundamental issue of economic growth.

\section{The Impact of Knowledge Distribution on Economic System}

The distribution of knowledge referred to here is the distribution of knowledge among people according to certain rules, while the distribution of knowledge per capita reflects the average level of knowledge among people. When discussing, it can be assumed that for an individual, the knowledge stock of human value that he acquired initially (hereinafter referred to as knowledge for the convenience of discussing) is the basis of his analysis. Such an analysis is based on the fact that "the analysis of what people will do can only begin with what they know" [2], rather than simply building the analysis on a group action hypothesis, so that the basis of the analysis is closer to the fact that economic growth comes from the coupling of behavioral patterns that everyone 
specifically recognizes. Therefore, the analysis of the impact of knowledge on the economic system should be based on this basis, which is also what North pointed out: "Institutions are human creations, they are evolving and changing for human beings, so our theory must begin with the analysis of individuals"(North,2014). In the further study, we can set up a social economic region with enough population. By setting up the individual knowledge stock, we can know that for the social economic region with enough individuals, the total amount of knowledge is the sum of all individual knowledge. This is because the number of people plays a very important role in economic growth. Economic growth must be based on the sufficient number of individuals in a population. A small group of simple individuals can not achieve the goal of economic growth in the modern sense. Therefore, it can be set that the number of people in a certain socio-economic region is large enough, and because there are different groups in such a socio-economic region. People have different knowledge structures, so the distribution of knowledge among people should be based on this. Here, our research focuses on the impact of the knowledge structure of the population on the system. This is because there is no institutional problem in terms of only the knowledge possessed by an individual. A single individual can only adapt to the arrangement of the system and can not create a system endogenously. Although there are many disputes about this point in economic research, the formation of endogenous system is always attributed to the situation of the population. We agree with Maynard Smith's view that "individual choice does not necessarily lead to optimal or sub-optimal social outcomes" (Ferromon, 2003), but depends on the outcomes of group selection. This choice depends on the level of people's grasp of value knowledge in terms of the institutional environment in which the group is located. This level can not be simply calculated as an average, but depends on the distribution of knowledge per capita. After making such a judgment, we can effectively solve the problem of rational or limited rational choice in economics. The so-called bounded rationality is only the limited accumulation of knowledge, so there are errors in judging some problems. However, in the long run, the growth of knowledge accumulation can conform to the principle of rationality. As Becker pointed out, "what economists believe is giving given preferences, and what is vaguely attributed to human nature or some other analogue -- the enduring emphasis on selfishness, altruism and social differences among relatives, and other aspects of preferences -- can be largely attributed to following suit. Over time, the choice of survival value with greater genetic adaptability has been proved to be explained "(Becker, 1976). This is because in the long run, altruistic behavior, contrary to the hypothetical selfish rational behavior, is formed on the basis that the knowledge stock acquired can make a long-term benefit to the event, and ultimately enable the population in a socio-economic region to satisfy the hypothesis of complete rationality.

Another thing to see is that the population is composed of individuals. When the population reaches a certain number, it can be approximated as a continuous series of functions. Therefore, it can be assumed that the knowledge distribution of the population is continuous. From the relevant theorem of mathematical statistics, we know that as long as the number of samples is large enough for any population, the mean value of samples obeys the normal distribution approximately. Therefore, when we analyze the distribution of knowledge in the population, we can also use the normal distribution to study. As far as our previous assumptions are concerned, the economic significance of the average level of knowledge reflected in this socio-economic region, i.e. the sample mean, is reflected in the level of knowledge distribution stock per capita that the economic system can achieve. Because logically speaking, people's decision-making for the future depends on their grasp of the past, which is reflected in the level of population, which is the level of knowledge stock per capita in a socio-economic region. This level of knowledge stock per capita is the level of certainty of the value of the population, which is reflected in the social economy. The average predictive level of population on economic growth in the economic region.

What we need here is the knowledge level of the people reflected by the per capita knowledge situation in a socio-economic region, and then the knowledge tradition constraints determined by the per capita knowledge distribution, which are finally embodied in the rules of the system. Therefore, the increase of population knowledge stock will constantly change the per capita knowledge situation, and the change of knowledge stock will lead to institutional evolution. "The accumulation of knowledge stock has played a subtle role in the long-term changes of political and economic systems" (North, 2013). This imperceptible effect is reflected in the fact that with the growth of knowledge in this area, not only the intensity of knowledge accumulation with common characteristics has been formed, but also the direction of value has been strengthened, and the direction of value will form a potential institutional arrangement of knowledge tradition for individuals in this economic and social region. Here, we should point out that when the population in the social and economic region is large enough and the individual gains a certain amount of knowledge increment, no matter whether the vector and the value of the increment are positive or negative, the change of the knowledge stock of random individuals does not necessarily lead to the change of the level of knowledge distribution per capita, so it will not be necessary. However, it leads to the evolution of the system (Zhang Shangyi, 2014). However, when the total knowledge 
level of the population changes, the distribution of knowledge per capita will change accordingly, which will change the level of knowledge per capita in the socio-economic region. When this happens, the per capita distribution of knowledge will affect the evolution of the system, and then form the institutional arrangements and environment that affect economic growth.

\section{Institutional Evolution Caused by Per Capita Knowledge Distribution}

In this part, the concept of negative knowledge is introduced. In the past, it has been determined that value knowledge is vector knowledge. Therefore, when value knowledge plays an opposite role in promoting the evolution of economic system, this kind of value knowledge is negative knowledge. Relevant theories of welfare economics show that not all institutional changes are conducive to improving the welfare of the population. Even the weakened welfare improvements pointed out by Hicks et al. can not be achieved in some countries and regions. What is the reason? This is because, from the perspective of knowledge distribution, some socio-economic regions are concerned with price. The knowledge of value presents the opposite direction to the evolution of institution, which further illustrates the basic judgment that the knowledge of value given by us is vector knowledge. In the case of negative knowledge, we can also understand from practice why some countries and regions have the opposite direction in economic development. In reality, we can observe the fact that there are some economic systems that are not conducive to economic growth, while behind the economic system, there is actually a fact that value knowledge is negative relative to economic growth.

Here, the question that must be solved is why the distribution of value knowledge changes. From the history of the evolution of human system, the shortage of technological resources can lead to the change of value knowledge. To illustrate this point, we can cite examples of the industrial revolution. The reason for the emergence of the industrial revolution in Europe lies in the shortage of human resources to a certain extent, which makes human beings have to think about the corresponding value knowledge, and the evolution of value knowledge leads to the emergence of a new system. As Heraly pointed out, "The order constructed by imagination does not lie in the subjective understanding of individuals, but in the common imagination of tens of millions of people"(Heraly, 2014). The imagination he pointed out was actually the result of the cognitive revolution, which he attributed to "culture is the main achievement of the cognitive revolution"(Heraly, 2014), and the culture he pointed out here is actually the system constructed by knowledge to maintain the order of the crowd. Although Heraly did not clearly point out this point, he hinted at the institutional arrangements determined by the collective knowledge which is different from human beings in the course of human history, when discussing the origin of the cooperative development of human beings. This common knowledge, which exists in tens of millions of people, is not only the knowledge tradition that Hayek means, but also the per capita knowledge level specified in this paper. At the same time, from the theory of mathematical statistics, we can know that the per capita knowledge level depends on the distribution of knowledge and the number of people. From this, we can draw the conclusion that the distribution of knowledge per capita determines the optimization level of the system.

Then, how can the knowledge status of the population promote the evolution of the system? The conclusion is due to the difference of value knowledge among different groups of the population. North clearly pointed out that "the change of knowledge is the key to economic evolution" (North, 2013), in which "the intentions of participants are reflected by the institutions they gradually formed" (North,2013). Here, although North does not specify the relationship between intentionality and knowledge, we can better understand it by dividing knowledge into two aspects, because the system reflects value knowledge, so when intentionality changes, it will inevitably promote the evolution of the system. Here, the question to be answered is how intentionality evolves. This is due to the existence of disadvantaged groups in any economic system, which have a demand for improvement of the economic system(Zhang Shangyi,2014), and the degree of such demand is determined by the disadvantage of the group. Considering that the economic system is determined by the distribution of knowledge per capita, the difference of groups with different requirements for the evolution of the system itself is reflected in the difference of the per capita value of value knowledge among different groups in an economic and social region. The greater the difference of knowledge per capita among different groups, the greater the possibility of economic system evolution. Recent studies have also shown that when economic technology becomes universal, it will inevitably lead to a gradual decline in growth. The solution to this problem lies in the improvement of both the institutional and knowledge sectors (Zhang Ping, Liu Xiahui,et al, 2015). Here, although the system and knowledge are confused, we have begun to find out the reasons from these aspects. When we attribute the causes of economic system to the level of per capita knowledge, then different groups with different distribution of per capita knowledge in an economic and social region become the driving force of economic evolution, which also shows that "the first general argument we must consider is that there are some government activities." Motion 
can make competition more effective and beneficial than without these activities"(Hayek, 1989). This is because, when the development of a socio-economic region depends more on small values, there will be more differentiated endogenous knowledge structures and institutional models in a socio-economic region, and these relatively differentiated knowledge structures will have requirements for institutional evolution, which will make a society come out. The possibility of institutional evolution is increasing. This situation can also explain the need to prevent monopoly. Because monopoly will lead to the consolidation of knowledge in a socio-economic region, thus restricting the evolution of the industry. This is consistent with Prescott's research and our observation of economic reality. "Because in history or in today's world, there are growing, stagnating or declining economies at the same time... If poor countries are poor because they are victims of institutional structures that impede growth, then is the institutional structure imposed externally or endogenously or is it a combination of the two?"(Ostrom, 2012). Through the study of the distribution of per capita knowledge and the institutional evolution of its mapping, we can conclude that institutions can be both internal and external. Raw, also related to external imposition. Through the analysis of knowledge accumulation, we can see that the evolution of the system is related to the distribution of knowledge per capita in a socio-economic region. The distribution of knowledge per capita ultimately depends on the overall level of knowledge accumulation of individuals. The endogenous system comes from the distribution of knowledge per capita, while the externally imposed system is based on the accumulation of knowledge. The way of knowledge distribution affects the level of knowledge distribution per capita, because the knowledge formation constituting the system has the vector and effect on the formation of individual knowledge in the socio-economic region. This also explains why the imposed external system always influences people's norms of conduct in a gradual way and gradually becomes an applicable institutional arrangement. Therefore, when we focus on the distribution of knowledge, we can explain the evolution of the system through the role of knowledge. It needs to be further clarified that human knowledge can not be complete, so it needs a way of continuous exchange and acquisition of knowledge, and more importantly, how to keep the knowledge of different groups and individuals different in the process of exchange, which may be more important in promoting the evolution of the system.

\section{The Path from Institution to Economic Growth}

The evolution of the system in a socio-economic region depends on the distribution of knowledge per capita, that is to say, when the level of knowledge distribution per capita increases, it will promote the evolution of the system, which has been demonstrated before. The economic performance of the system has also been solved by scholars including North. "Incentive is the fundamental determinant of economic performance" (North, 2014) But we still need to understand how the system leads to growth. Although North has pointed out that "institutions affect economic performance through their impact on exchange and production costs" (North, 2014), he also argues that "institutions are not necessarily or usually not created to achieve social efficiency, but rather they are created to serve negotiations with new rules. The interests of competent people"(North, 2014). Although the evolution of institutions leads to economic growth, it is not clear what path to follow. North also clearly pointed out that the path from institution to economic growth is not very clear, and pointed out that "it will be very valuable to clarify which institutional characteristics shape performance"(North,2014). The focus of this part is to explore and solve this problem, so as to build a clear path from the system to the economic growth rate, which is also the focus of this paper.

From institution to economic growth, there must be an intermediate part, rather than the direct relationship between institutional change and economic growth as analyzed by the New Institutional Economics School. To solve this problem, we must start from the composition of personal knowledge we analyze. Individual knowledge is divided into knowledge about human value and knowledge about technology. The former determines the evolution of the system, while the latter constitutes and can be deepened into the evolution of technology, and economic growth to a large extent should be attributed to the result of technological progress. This can also be concluded from the history of human development. In China, for example, a considerable part of the history of civilization has been wandering in population expansion and social unrest for thousands of years. One of the important reasons is that the economic growth provided by technology may not meet the needs of population growth, which leads to social unrest and the sharp decrease of population, until the technological progress of the Ming and Qing Dynasties. Real economic growth has been achieved. Recent studies have also pointed out through quantitative analysis that "if developing countries want to surpass developed countries, they can only improve the external environment of R\&D sector, improve the level of human capital, and then enhance knowledge productivity" (Su Zhiqing, Wang Yufeng, 2012). If institution is the cause of affecting economic performance and technology plays a very important role in economic growth, then the path between institution and economic growth may be that institution plays a role through technology, thus forming such a logical 
relationship in two kinds of human knowledge: value knowledge determines institution The evolution of system determines the progress of technology and economic growth. In this regard, we can further demonstrate.

Here, we can consider that technology is the function of the system, and set the level of knowledge about the system per capita, which can reflect the level of the system. Then we can deduce the level of technology that can be generated spontaneously and absorbed in the per capita distribution of human knowledge. As the evolution of the system depends on the distribution of knowledge per capita, it is difficult to realize the evolution of the system in the socio-economic region, and at the same time, it is difficult for technological progress to fundamentally form and promote the economy, in view of the historical development practice of China, when the knowledge stock of the standard of conduct, such as the formation of Confucianism, is almost similar to that of the whole people. The power of growth does not lie in whether China attaches importance to the development of commercial economy, which will limit the economic growth in ancient China.

Knowledge of human values directly affects human behavior and judgment of problems, thus affecting the evolution of regional social and economic systems. As North pointed out, "The role of the actor's concept in the system is more important than its role in technological change, because ideological beliefs influence the subjective constructive model of decision-making" (North, 2014), and this subjective constructive model is, in the final analysis, what we have pointed out about human price. Value knowledge, and thus formed a social and economic region of the system and the implementation of institutional constraints. This evolution has enabled a socio-economic region to spontaneously produce new technologies and possibly introduce new technologies, and then produce knowledge increment effects such as those proposed by Romer and others, thus solving the problem of coordination between economic and population growth. Although North also proposed that "system and technology together determine transaction costs" [13] p74, it did not explain the logical relationship between them. Therefore, he can only put forward the system as an extremely important variable in the growth function from the qualitative point of view, but also has to admit that" there is no strict one-to-one correspondence between rules and performance in fact" (North, 2014), the reason is that he has not really found out the distribution of the system by the per capita knowledge of human values. The origin of the state. As Barrow's analysis of education and growth points out, "The theory that education has a positive effect on an economy's ability to absorb new technologies" (Barrow,2004), the reason is that education not only disseminates knowledge about technology, but also imparts knowledge about human values, and the distribution of knowledge about human values determines society. The possibility of institutional evolution in economic regions makes endogenous technological progress and technology introduction possible. In the analysis of the correlation between education and economic growth, Barrow argues that "early education seems to play a role in democratization" (Barrow,2004). Through the observation of the educational process, we can also understand that early education is more about the education of value knowledge and less about the education of technical knowledge, which may be the closest argument about the evolution of human value knowledge determining system. These conditions also further prove the logic of economic growth proposed in this paper from the per capita distribution of human knowledge. As the real economic growth took place in modern times, it can be further demonstrated. As Wang Dingding pointed out, "It is only in recent centuries that human society has developed so-called (that is, per capita income has increased by more than $2 \%$ per year). In the long history of society, the annual growth rate of per capita income has almost always remained zero "(Wang Dingding, 1998).

A review of economic growth in the 20th century can also clearly demonstrate this. North clearly pointed out: "In the Middle Ages, there was progress in technology, although the process was hindered by the cold social fashion. Because there is no institutional guarantee, the inventor's personal rate of return is equal to the social rate of return"(North et al,1989).This is precisely because there is no favorable institutional environment for technological gains at the institutional level, so technological innovation can not form effective productivity in the whole society even if it occurs. "In this way, the productivity increase that constitutes economic development will be weakened or delayed" (North et al, 1989) For this reason, the lack of institutional environment for technological innovation and technology introduction hinders the evolution of technology. "Because of different institutional structures, countries with similar resource endowments may have different development paths. Because the system affects the power of a country to improve and develop new technologies". In his related studies, Van Gaster clearly pointed out that "the independent power of local governments in economic affairs the de facto federalism - played a key role in the emergence of the industrial revolution."(Wengast, 2013) And it is precisely pointed out that this is because in almost all business centers, the management of guilds restricts competition, pricing, entry and training, and therefore it is impossible to accumulate new knowledge in the industry, thus hindering the evolution of the system. This is also why industrialization did not appear in existing business centers. Reason. We know that economic growth in the true sense originates from technological 
progress caused by the industrial revolution, and thus completely changes the pattern of population expansion caused by economic growth in the form of extension, which ultimately makes the economy unable to support the needs of population expansion and leads to social chaos, so that human social and economic growth can support population expansion. Need.

\section{Concluding Remarks}

Through the previous analysis, we can see clearly that when knowledge is used as the basis of economic analysis and knowledge can be properly divided into knowledge about technology and knowledge about human value, some problems in economics can be solved better, which is in line with the progress of human civilization. Generally speaking, the history of human development is how to adapt and transform technology so that the uncertainty of technological evolution can be gradually grasped by means of technology. In this process, various kinds of human values have higher and higher requirements for certainty. If there is no certainty grasp of human values, then ultimately. It is impossible to grasp the certainty of technology, especially to promote economic growth by using technology. This can be proved by the history of each country and region and what is happening. Therefore, the deterministic grasp of group activities should become the ultimate decisive factor of economic growth.

At the same time, it can be found that promoting the determination of human value is closely related to human value choice, which is rooted in the knowledge of human value, and the progress of this knowledge is the basis of human value determination. Through relevant research, we can find that the progress of promoting human value knowledge mainly depends on two aspects: one is the difference of per capita knowledge level among different groups in the economic and social region, the other is related to the number of people, and the per capita knowledge progress is negatively related to the number of people, thus making the system black box problem in one. To a certain extent, it has been solved. On this basis, it can be inferred that there is a positive correlation between economic system and technological progress. Because technological progress has an obvious effect on economic growth, the logical sequence of knowledge progress, institutional evolution, technological development and economic growth can be constructed, so that the final decision of economic growth can be more clearly recognized. The factor lies in the progress of knowledge of human values, which also solves the problem of economists' interpretation of economic growth in developing countries, so that economic theory can be more consistent with different countries and regions. However, up to now, the quantitative relationship between the three can not be accurately obtained, which is the direction of further research.

\section{References}

Afried, M. (1983). Principles of Economics [M]. Zhu Zhitai, Translated. Beijing: Commercial Press, 1983.

Barry. R. W. G. (2013). Constitutionalism as a Governance Structure: Political Basis of Security Market[M]. Transaction Cost Politics. Liu Yaping, Translated. Beijing: Renmin University Press, 92-109.

Becker. G. S. (1976). Altruism,egoism,andgenetic fitness: Economics and sociobiology[J]. Journal of Economic Literature, 14(3), 817-826.

Douglas, C. N. (1994). Structures and Changes in Economic History [M]. Chen Yu, Translated. Shanghai: Shanghai People's Publishing House, 1994.

Douglas, C. N. (2013). Understanding the Process of Economic Change [M]. Zhong Zhengsheng, Xinghua, Gao Dongming, Translated. Beijing: Renmin University Press, 2013.

Douglas, N., \& Robles, T. (1989). The Rise of the Western World [M]. Li Yiping, Cai Lei, Translated. Beijing: Huaxia Publishing House, 1989.

Douglas. C. N. (2014). Institution, Institutional Change and Economic Performance [M]. Hanghang, Translated. Shanghai: Gezhi Publishing House, 2014.

Eleanor, O. (2012). Evolution of Collective Action and Social Norms [J]. Wang Yufeng Translated. Comparison of Economic and Social Systems, 5, 1-13.

Feng, H. F. A. (1989). Individualism and Economic Order [M]. Jia Zhan, Wen Yuelan, Translated. Beijing: Published by Beijing Institute of Economics, 1989.

Jack. J. F. (2003). Economic Evolution-Exploring the Theoretical Basis of New Institutional Economics [M]. Li Zhenming, Translated. Beijing: Economic Science Press, 2003.

Juval, H. (2014). A Brief History of Human Beings - From Animals to God [M]. Lin Junhong, Translated. Beijing: CITIC Press, 2014. 
Robert, J. (2004). Barrow. Determinants of Economic Growth [M]. Li Jian, Translated. Beijing: Renmin University Press, 2004.

Robert. M. S. (1991). Technology Change and Total Production Function [J]. Analysis of Economic Growth Factors. Beijing: Commercial Press, 1991.

Romer, P. M. (1986). Increasing return and long-rungrowth [J]. Journal of Political Economy, 94(5), 1002-1037. https://doi.org/10.1086/261420

Schneewind, J. B. (1990). Moral philosophy from montaigne to Kant [M]. Cambridge: Cambridge University Press, 1990.

Stephen, G. P., Edward, L. P. (2013). The Barrier to Wealth [M]. Su Jun, Translated. Beijing: Renmin University, Press, 2013.

Su, Z. Q., \& Chen, Y. E. (2014). Knowledge trade, technological progress and economic growth [J]. Economic Research, 8, 133-145.

Theodore. W. S. (1990). On Human Capital Investment [M]. Wu Zhuhua, Translated. Beijing: Beijing Academy of Economics Press, 1990.

Wang, D. D. (1998). The Basis of Economic Rationalism [J]. Sociological Studies, 2, 3-13.

Zhang, P., \& Liu, X. H., et al. (2015). New Factor Supply Theory, System and Policy Choice for Breaking through the Deceleration of Economic Growth [J]. Economic Research, 11, 4-19.

Zhang, S. Y. (1998). From Knowledge Tradition to Transaction Cost Payment [J]. Exploration, 1, 81-84.

Zhang, S. Y. (2014). Analysis of Knowledge Distribution and Economic Growth of Population [J]. Zhejiang Social Sciences, 5, 98-103.

Zhang, S. Y. (2014). Population knowledge distribution and economic growth analysis [J]. Exploration, 5, 98-103.

\section{Copyrights}

Copyright for this article is retained by the author(s), with first publication rights granted to the journal.

This is an open-access article distributed under the terms and conditions of the Creative Commons Attribution license (http://creativecommons.org/licenses/by/4.0/). 